\title{
Research Paper \\ Designing and Characterizing Nano-carriers Containing Nepeta Persica Extract and Their Effect on Bone Cancer
}

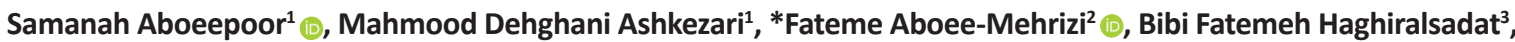 \\ Narges Nikoonahad Lotfabadi ${ }^{4}$
}

1. Medical Biotechnology Research Center, Ashkezar Branch, Islamic Azad University, Ashkezar, Yazd, Iran.

2. Department of Medicine, Yazd Branch, Islamic Azad University, Yazd, Iran.

3. Medical Nanotechnology \& Tissue Engineering Research Center, Yazd Reproductive Sciences Institute, Shahid Sadoughi University of Medical Sciences, Yazd, Iran.

4. Department of Biology, Faculty of Basic Sciences, Science and Arts University, Yazd, Iran.

\begin{tabular}{|c|c|}
\hline $\begin{array}{l}\text { Use your device to scan } \\
\text { and read the article online }\end{array}$ & \\
\hline 口is: & $\begin{array}{l}\text { Crtation Aboeepoor S, Dehghani Ashkezari M, Aboee-Mehrizi F, Haghiralsadat B, Nikoonahad Lottabadi N. [Designing and } \\
\text { Characterizing Nano-carriers Containing Nepeta Persica Extract and Their Effect on Bone Cancer (Persian)]. Quarterly of "The }\end{array}$ \\
\hline berizis & Horizon of Medical Sciences". 2020; 26(2):142-155. https://doi.org/10.32598/hms.26.2.3161.1 \\
\hline 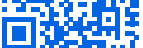 & dol'https://doi.org/10.32598/hms.26.2.3161.1 \\
\hline
\end{tabular}

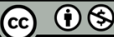

Received: 08 Jun 2019 Accepted: 13 Nov 2019 Available Online: 01 Apr 2020

Key words: Nepta persica, Noisome, MTT, MG63 Cell line

\section{A B S TR ACT}

Aims Niosomes have been considered as carriers for targeted delivery of drugs in modern drug delivery systems. The Iranian Nepta (Nepta genus) has unique biological properties; thus, this plant was used in this study to prepare the optimized formulation of niosomes containing extract, and to evaluate its cytotoxicity.

Methods \& Materials Initially, the extract of Iranian Nepta (N. persica) was prepared. Then, the nanoniosomal system, containing the extract was designed and synthesized using cholesterol and Span-60. The physicochemical properties of the system were evaluated by FTIR and SEM. MTT assay [3-(4,5-Dimethylthiazol-2-yl)-2,5-diphenyltetrazolium bromide] was used to determine the toxicity of the Nepta extract and nano-system containing it against bone cancer cells (MG63).

Findings An optimized formulation was obtained using cholesterol and Span-60 with a ratio of 80:20. The amount of extract release from this formulation continued with a steady slope over a long period of time. The survival rate of MG63 cells against $100 \mu \mathrm{g} / \mathrm{mL}$ of the free form of $\mathrm{N}$. persica extract and its niosomal form were $22 \%$ and $8.88 \%$, respectively.

Conclusion The present research results suggested that $\mathrm{N}$. persica extract exert anti-cancer effects and niosome could improve its anti-cancer efficiency. Therefore, it could be used as a proper carrier to deliver the extract to the target tissue.

\section{Extended Abstract}

\section{Introduction}

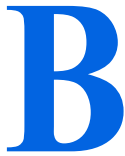

one cancer is an early mesenchymal tumor, i.e. histologically characterized by the production of steroids by malignant cells. It is a relatively rare malignancy and the most frequent bone malignancy. Available treatment methods often have severe adverse effects; thus, implementing medicinal plants, like Iranian nepeta (Pooneh-sa) and their derivatives has received significant attention. It is hoped that these plants, which have fewer adverse effects, could be more effective in fighting cancer cells. In modern pharmacology, numerous efforts have been made to improve drug delivery and optimize its pharmacological performance. A measure to solve this problem is applying nanotechnology, and consequently, using carriers, like niosomes. As two-

\section{* Corresponding Author:}

\section{Fateme Aboee-Mehrizi, PhD.}

Address: Department of Medicine, Yazd Branch, Islamic Azad University, Yazd, Iran.

Tel: +98 (35) 38210540

E-mail: aboeef@yahoo.com 
layer carriers, niosomes are ideal models of biological cell membranes that work by minimizing the harmful effects on cell and tissue health.

Niosomes are carriers composed of cholesterol hydration with non-ionic surfactants in the aquatic environment; they could trap materials. Due to their biocompatibility and biodegradability along with nanoscale size, these carriers have demonstrated numerous applications in various fields, including cancer treatment [3]. The general tendency of society to use herbal medicines and natural products is increasing. Furthermore, a large share of commercial pharmaceutical products belongs to herbal medicines [4, 5]. Herbs have long been implemented to treat various human diseases. Genus Nepeta (of Lamiaceae family), known as "poone-sa" in Iran, contains different annual and perennial species. It is found in different parts of Asia, Europe, and North Africa. Approximately 250 species of this genus have been reported in different parts of the world [8]. The genus nepeta in Iran has 67 wildling species, i.e. distributed in various regions of Iran and are mostly indigenous [12].

The present study aimed to investigate the anti-cancer properties of the extract of Iranian nepeta plants (Nepeta persica) and the niosomes containing this extract against bone cancer cells.

\section{Materials and Methods}

Bone cancer cells (MG63 cell line) were studied in cell cultivation conditions in DMEM plant growth regulator enriched with $10 \% \mathrm{FBS}$ in a $\mathrm{CO}_{2}$ incubator at $37^{\circ} \mathrm{C}, 5 \%$ $\mathrm{CO} 2$, and $95 \%$ humidity.

The MG63 cell line of bone cancer was obtained from the Cell Bank of Pasteur Institute of Iran. The extraction of the Iranian nepeta plant (Nepeta persica) was performed using the soxhlet apparatus. After drying, the dried extract was applied for further experiments. Thin-film hydration method was employed to synthesize nano-niosomes. The lipid phase consisted of span 60-cholesterol, which was formed by multiple mole ratios (F1-F3 formulations), using a rotating evaporator of a thin lipid film. Then, the thin lipid film was hydrated, homogenized, and filtered to reduce the size. After separating the free extract, the amount of the loaded extract was determined. Then, the physicochemical properties of the niosomes containing the extract, including their size and surface charge were evaluated. For this purpose, we applied a DLS and a Zetasizer device. Moreover, we evaluated it using the Scanning Electron Microscope (SEM) image of the morphology of the niosomes. Finally, the cytotoxic effect of the extract and the best formulation of the enzyme-containing niosomes (F2) were evaluated after 48 hours of treatment. We employed the MTT test on bone cancer cells for this assessment. Analysis of Variance (ANOVA) and Student's ttest was used in SPSS for data analysis (Table $1 \&$ Figure 1).

\section{Results}

Based on the loading rate of the extract in the niosomes, the F2 formulation with $79.11 \%$ loading was recognized as the optimal formulation; subsequently, it was used in other research stages. The size of the niosome nano-carrier, containing the extract was 108.6 nanometers. Besides, the surface load of the niosome nano-carrier, containing the extract averaged $-38.02 \pm 1.18 \mathrm{mV}$. The SEM image suggested that the particles had the right size distribution and spherical structure and were agglomerated. The MTT test results indicated that the survival rate of the cells against these two samples was $22 \%$ and $5.88 \%$, respectively. Thus, at the same concentrations, the niosome system significantly destroyed a higher percentage of cancer cells.

\section{Discussion}

In 2014, Abolfazl Shakeri et al. examined the chemical compounds and antibacterial activity and cell toxicity of Nepeta ucrainica. They concluded that the extract of this plant presented antibacterial activity, especially against gram-positive bacteria. It also controlled the growth of ovarian cancer and breast cancer (MCF-7). Eventually, cytotoxic activity was associated with significant doses against MCF-7

Table 1. Different nanoparticle formulations and the percentage of compounds used in these formulations

\begin{tabular}{cccc}
\hline Formulation Code & Span 60 (\%) & Cholesterol (\%) & The Initial Concentration of the Extract $(\mu \mathrm{g} / \mathrm{mL})$ \\
\hline F1 & 90 & 10 & 5000 \\
F2 & 80 & 20 & 5000 \\
F3 & 70 & 30 & 5000 \\
\hline
\end{tabular}



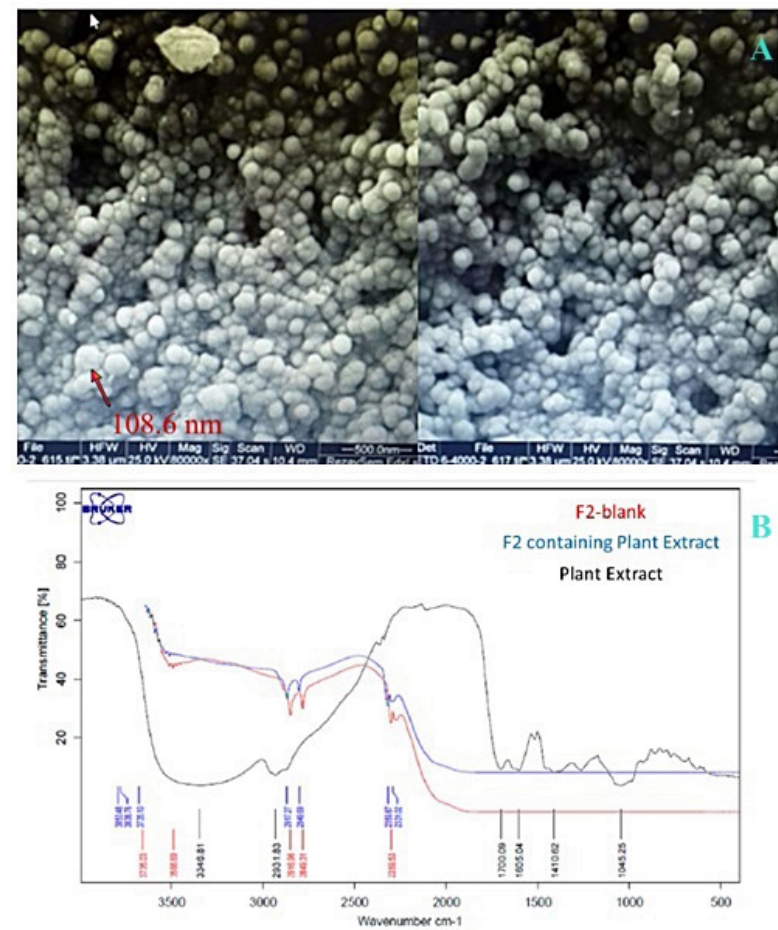

Quarterly of

The Horizon of Medical Sciences

Figure 1. A. Electron microscopy image of nano-niosomes containing extracts; B. Overlapping of the FTIR analysis of the extract-free system with red color (F2: blank), a system containing a blue extract (F2: containing plant extract), and a black extract (plant extract)

and A2780 [17]. Askari et al. investigated the effect of cellular toxicity of pomegranate skin extract in the form of niosomes on breast cancer. They stated that using niosomes as a carrier improves the extraction process and further reduces the survival rate. In addition, the release rate and effectiveness of the extract in the condition of cancer cells (in terms of temperature and $\mathrm{pH}$ ) are better than nanocarriers. Such data signify that their study findings are consistent with those of the present study [23].

Using other nanocarriers to load the extract of Iranian nepeta plants and comparing it with the current research findings could provide the best nanocarrier that could induce this plant's maximum anti-cancer properties.

Apart from the high cost of materials and services, there were no restrictions for conducting the present study.

\section{Conclusion}

The obtained data revealed the higher effectiveness of nano niosomic form of the extract of Iranian nepeta plant, compared to the free form of the extract; such efficacy regarded the ability to enter the cell and induce anti-cancer effects.

\section{Ethical Considerations}

\section{Compliance with ethical guidelines}

The Medical Ethics Committee of the Islamic Azad University, based on letter No. 98975, has approved this research in terms of biological ethics.

\section{Funding}

This research did not receive any specific grant from funding agencies in the public, commercial, or non-profit sectors Authors' contributions

All authors contributed in designing, running, and writing all parts of the research.

\section{Conflicts of interest}

The authors declared no conflict of interest.

\section{Acknowledgment}

The authors express their gratitude to the School of Paramedical Sciences of Yazd Shahid Sadoughi University of Medical Sciences. 


\section{طراحى و مشخصهيابى حامل نانويى حاوى عصاره Nepeta persica و تأثير آن بر سرطان استخوان (رده سلولى (MG-63)}

سمانه ابوئىيور' ه، محمود دهقانى اشكذرى'؛ "فاطمه ابويى مهريزى' هـ، بعبى فاطمه حقير السادات"، نركس نيكونهاد لطفآبادى"

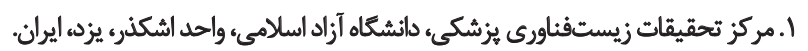

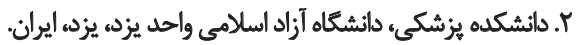

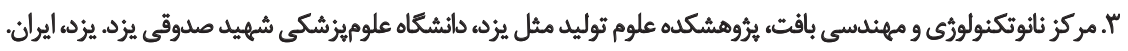

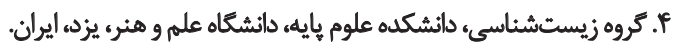

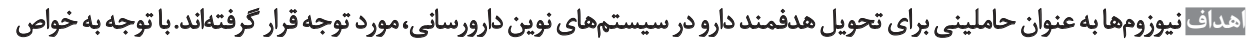

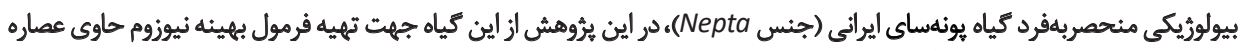

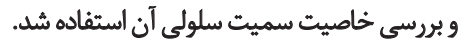

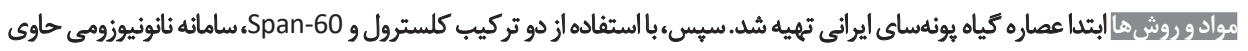

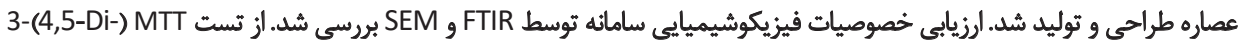
(methylthiazol-2-yl)-2,5-diphenyltetrazolium bromide سلولهاى سرطانى استخخوان (MG63) استفاده شد.

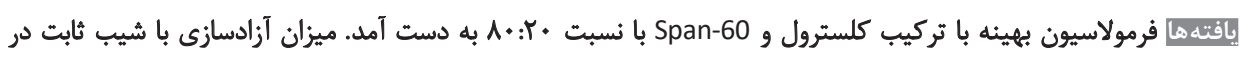

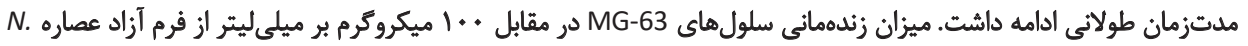
persica

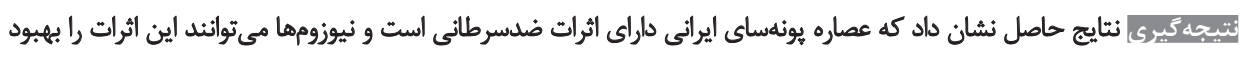

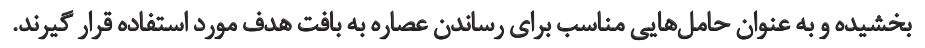

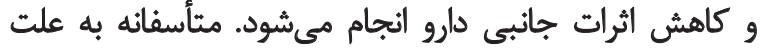

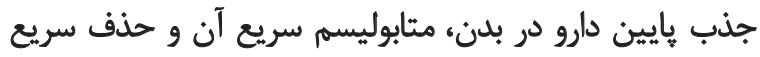

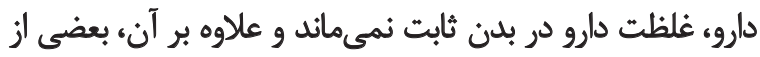

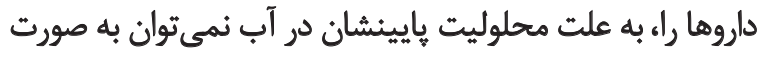

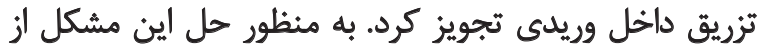

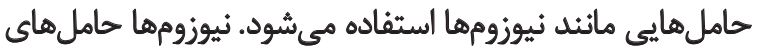

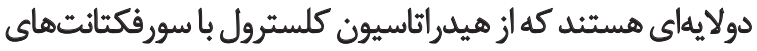

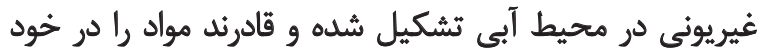

سرطان يكى از مهمثرين عوامل مركومير در سرتاسر جهان

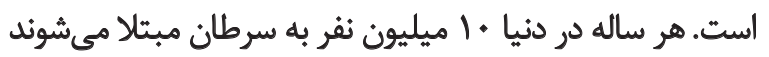

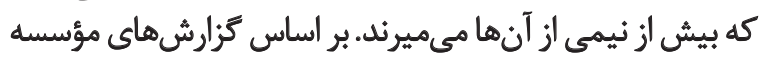

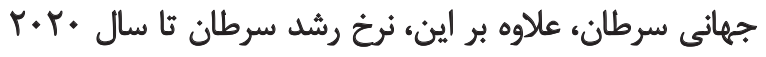

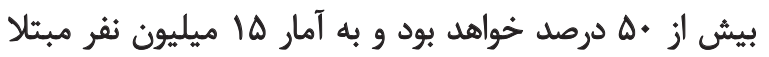

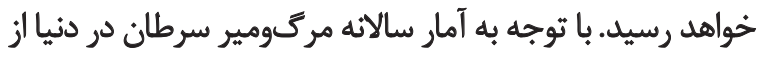

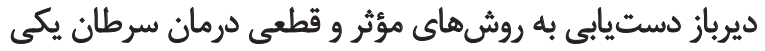

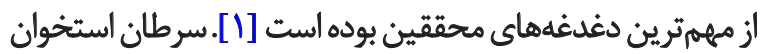

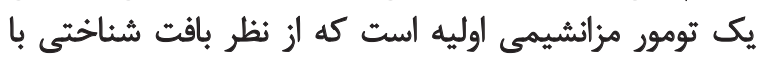

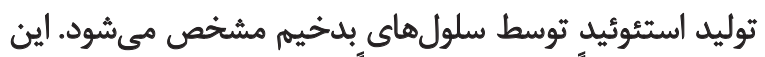

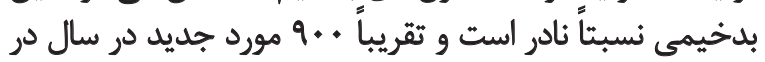

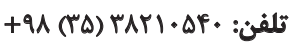
يست الكترونيكي: aboeef@yahoo.com 
كياهان دارويى يزد جمع آورى شد و توسط بخش كياهشناسى

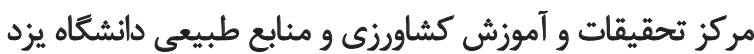

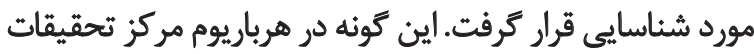

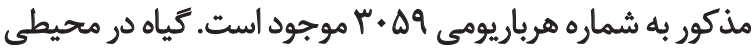

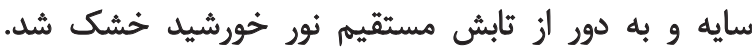

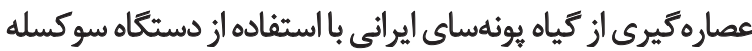

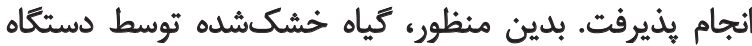

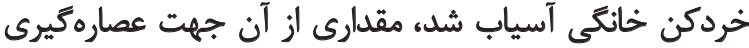

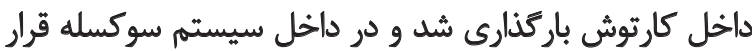

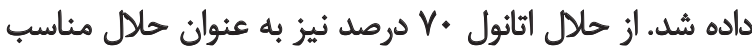

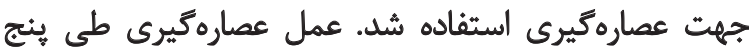

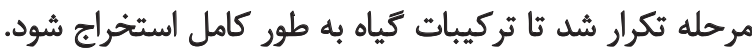

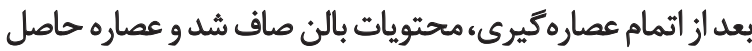

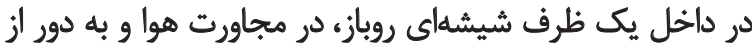

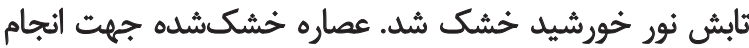
آزمايشات بعدى مورد استفاده قرار ترفت

ثمبيه و سيتئنانونيوزوم

از روش آبدهى فيلم نازك كه روشى كلاسيك در تهيه

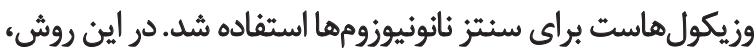

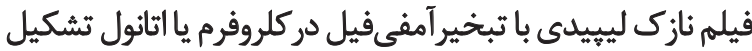

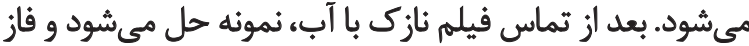

وزيكولى شكل مى كيرد [1T]

\section{أختاط قاز ليبيدي وتشكيل فيلم نازئ}

فاز ليبيدى شامل كلسترول-Span-60 (سيكما، آمريكا) است.

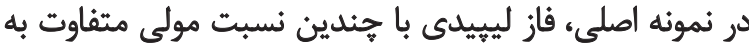

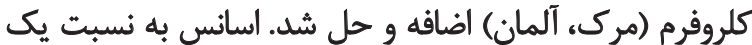

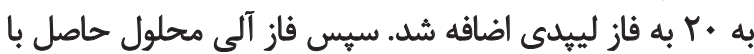

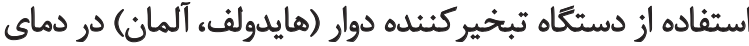

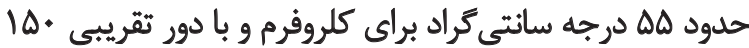

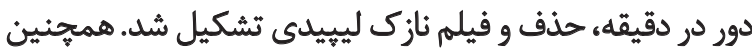

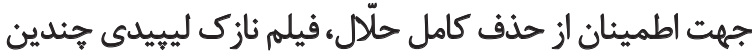

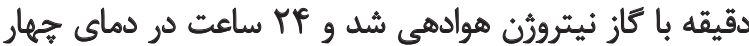

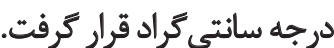

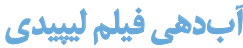

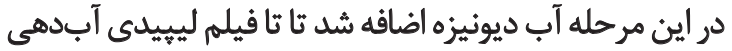

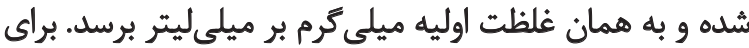

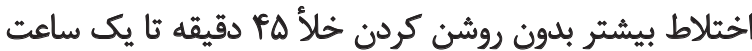

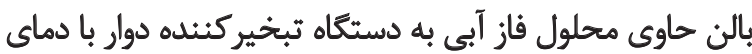

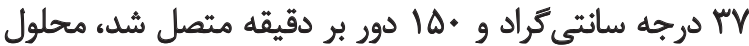

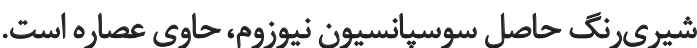

محبوس كنند. از لحاظ حلاليت، نيوزومها طيف وسيعترى از

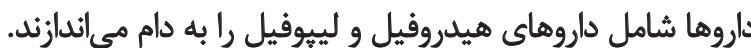

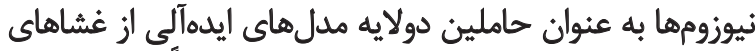

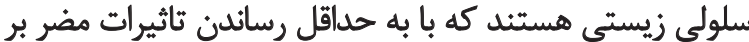

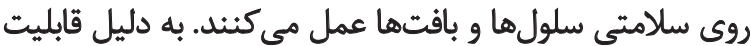

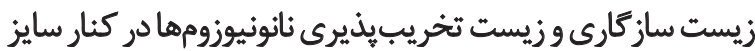

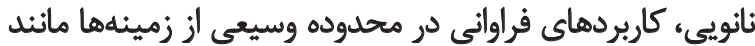

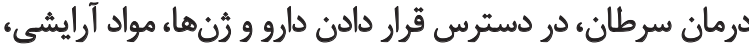
صنايع غذايى و كشاورزى نشان دادهاند [بان. امروزه كرايش عمومى جامعه به استفاده از داروها و درمانهاى

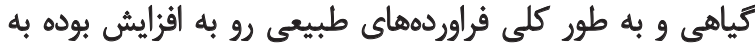

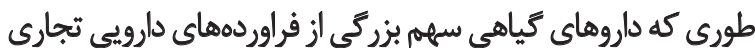

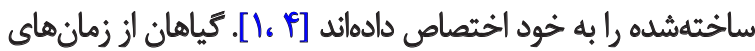
بسيار قديم براى درمان بيمارىهاى كوناكون انسان إندان مورد استفاده

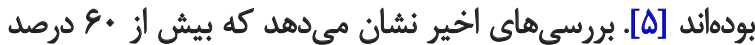

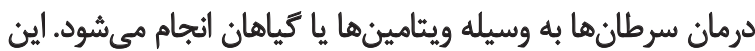

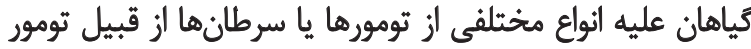

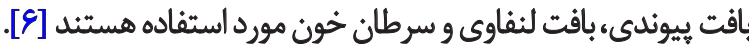
جنس Nepta (از تيره نعناعيان) كه در ايران با عثوان يونهسا

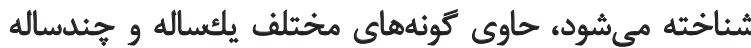

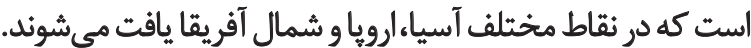

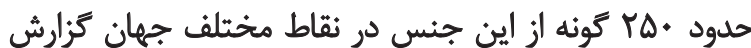

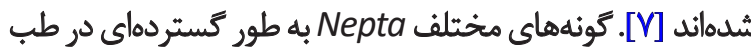

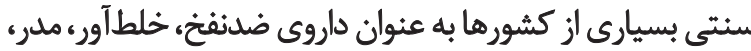

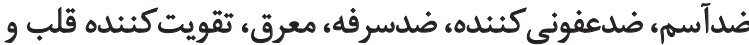

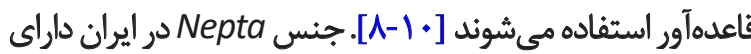

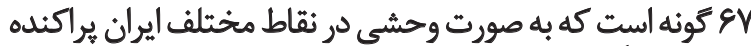

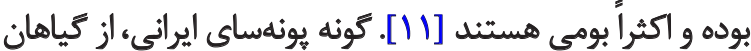
بومى ايران است كه در مناطق مختلف كشور رشد مى كند. در اين تحقيق، خاصيت ضدسرطانى كياه يونهساي ايرانى در برابر

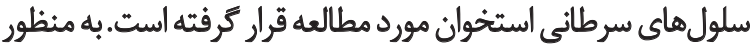

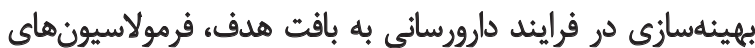

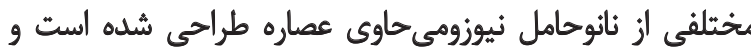

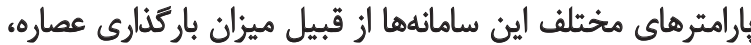

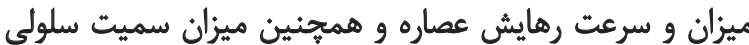

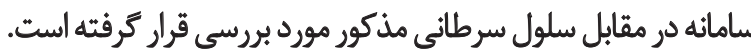

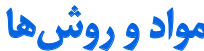

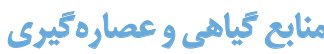
كياه يونهساي ايرانى' در فصل كلدهى از ايستكاه تحقيقاتى 
Instruments Corp

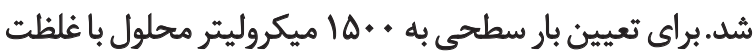
1/ إل ميلى كرم بر ميلى ليتر نياز است.

\section{تصويريو داري أز نائوئيوزوم}

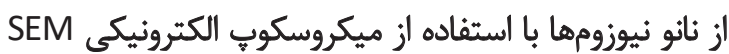

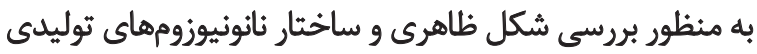

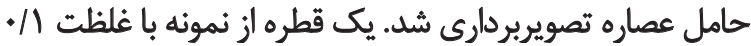

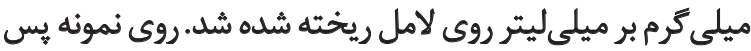

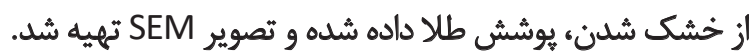

آناليز ثانوثيوزوم سثترشده توسط دستّاه طيفسئي مادون

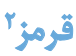

كروهاى عاملى سطح نانونيوزوم توليدشده توسط آناليز

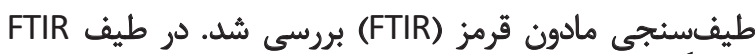

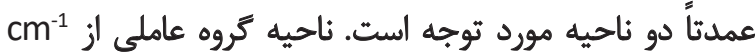

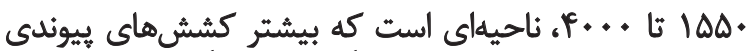

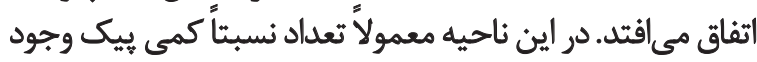

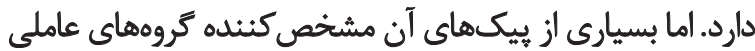

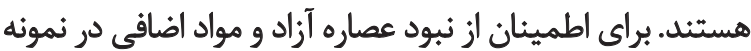

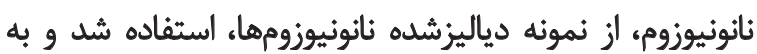

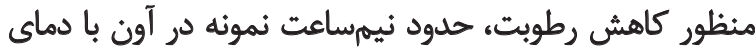
تقريبى •و درجه سانتى كراد قرار داده شد.

\section{بروسي ميزان بار تَّأوى عصاره داخل ثيوزوم}

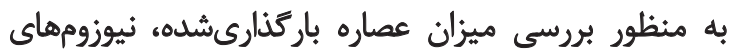

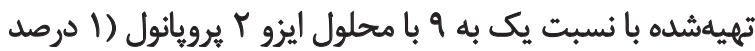

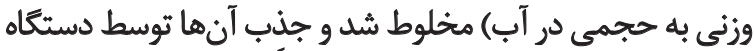

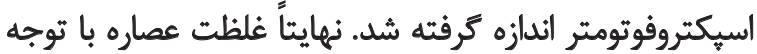

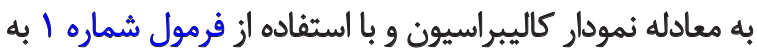

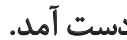

Entrapment Efficiency $(\mathrm{EE} \%)=$

$\frac{\text { Encapsulated Drug Concentration }}{\text { primar used drug concentration }} \times 100$

بروسي رونلد وهايش عصاره موجود دو نيوزوم

براى بررسى رهايش عصاره، حجم مشخصى از نيوزوم حاوى آن

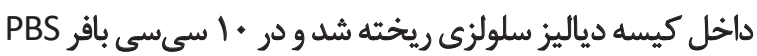

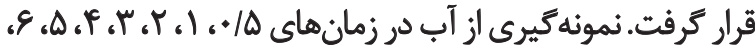

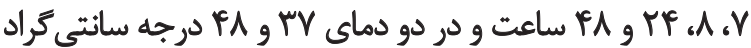

2. Fourier Transform Infrared Spectrometer (FTIR)
كاهش سائز

براى كاهش اندازه نيوزومهاى جندلايه بزرى و تشكيل

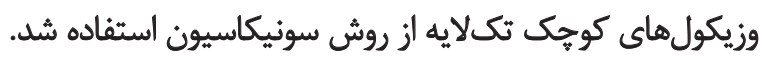

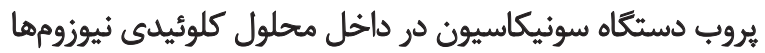

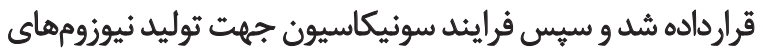

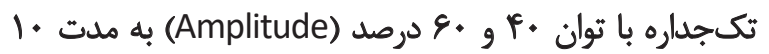
دقيقه (• ا ثانيه روشن و ها ثائيه خاموش) انجام شد.

علاوه بر كاهش سايز به روش سونيكيت بروبى، مي توتوان از

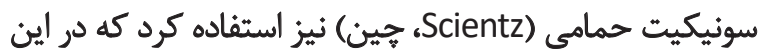

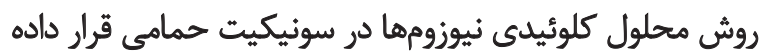

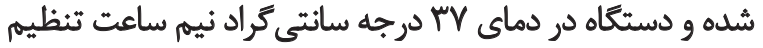

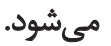
فر ايثداثيلتر اسيون

قبل از فيلتراسيون، ناخالصى و مواد اضافى نمونهها (همجيون

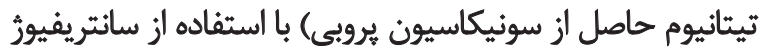

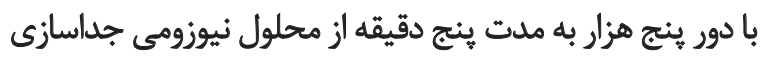

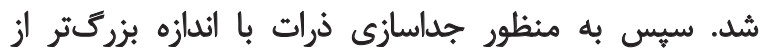

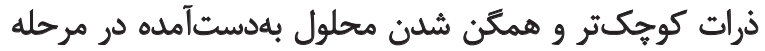

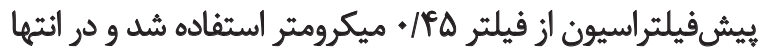

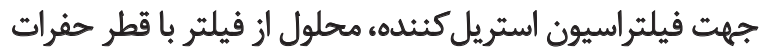
Tr/r/ ميكرومتر عبور داده شد.

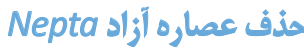

يس إز باركذارى عصاره به منظور جدا كردن عصاره

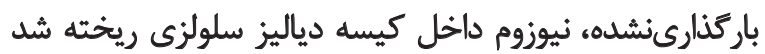

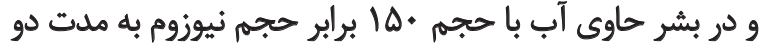

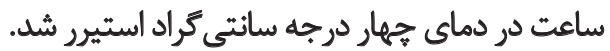

تعيين سايز و محدوده توزيع أندازٔه ناثوثيوزومهاي هاوى عصاره

محدوده توزيع اندازه ذرات و همجنين بيك اندازه ذرات با إنائ

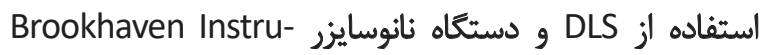
ments Corp

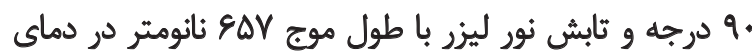

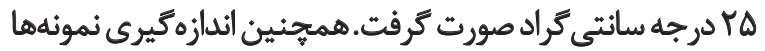

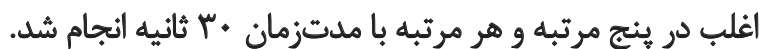

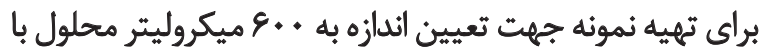
غلظت ه/ • - / / ميلى ترم بر ميلى ليتيتر نياز بود.

تعيين يتائسيل ز تأنانوئيوزوم

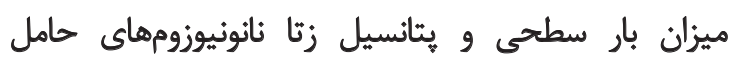

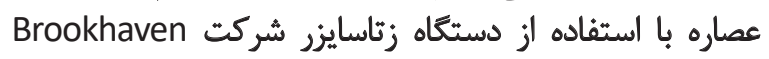


يافتهها

\section{N persica تعيين طول موج ماكسيمم عصاره}

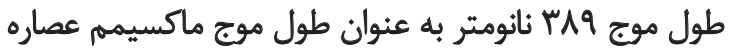

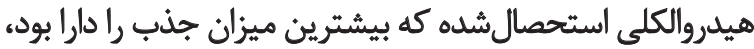
براي انجام آناليزهاي ثانويه انتخاب شدي كيد.

Nopta توليد ناثوثيوزوم حاوى عصاره

به منظور تهيه نانونيوزوم حاوى عصاره Nepta، سه فرمولاسيون مختلف (F1-F3) با استفاده از عصاره، كلسترول و وارئ

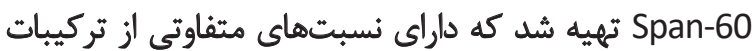

$$
\text { بودند (جدول شماره (). }
$$

با توجه به اينكه هدف از طراحى و بهينهسازى فرمولاسيون

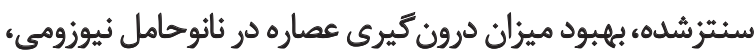

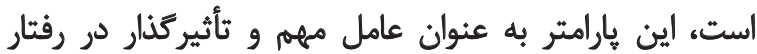

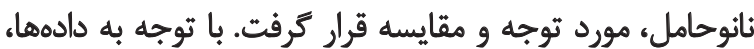

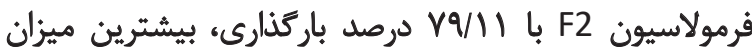

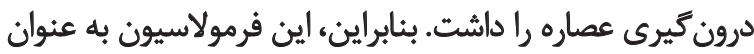

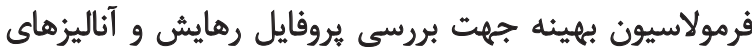

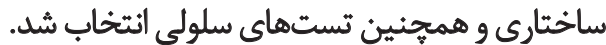

\section{بروسيى الكوى رهايش ثائوحامل ثيوزومي}

ميزان آزادسازى عصاره از نانوحامل نيوزومى در دو دو شرايط

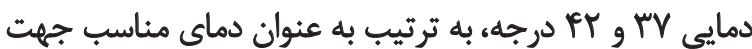

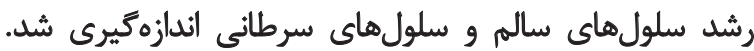

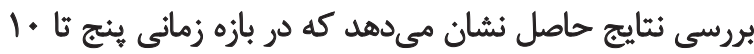

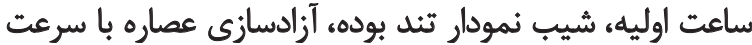

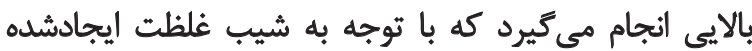

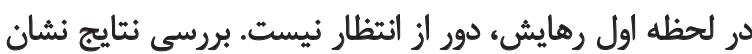

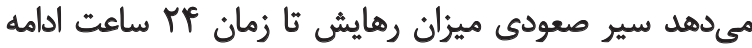

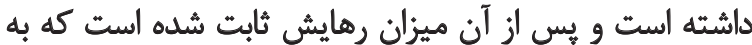

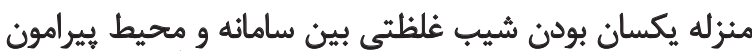
است. يّ از اين، نانوحامل با يك شيب شئ ثقريباً ثابت به به روند
انجام شد و جذب نمونهها توسط دستكاه اسيكتروفوتومتر مورد

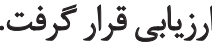

بروسي سميت سلولي نيوزومهاي حاوى عصاره در روش MTT به منظور تعيين سميت سلولى نمونهها در

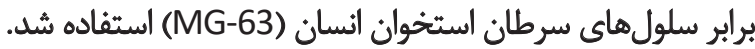

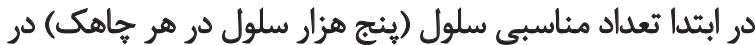

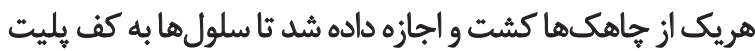

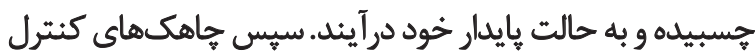

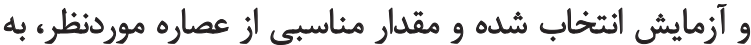

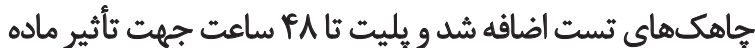

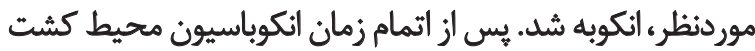

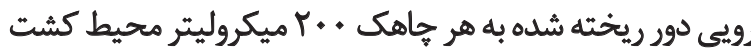

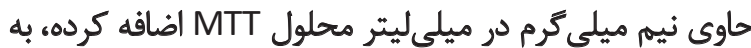

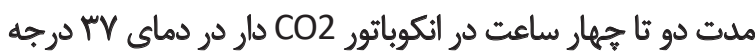

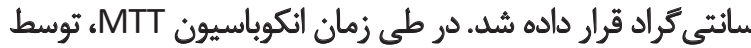

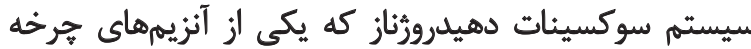

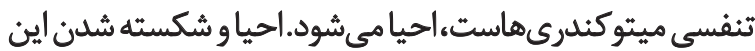

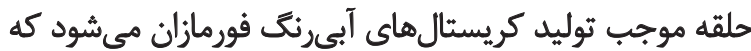

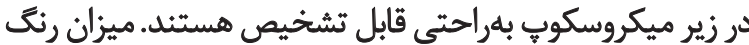

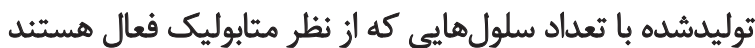

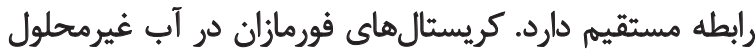

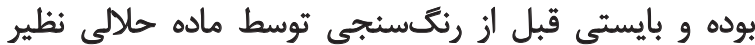

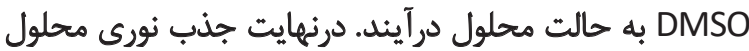

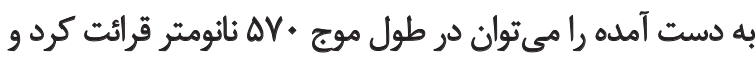

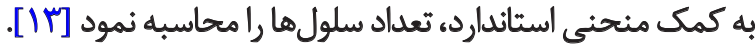

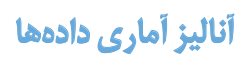

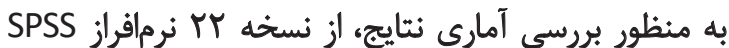

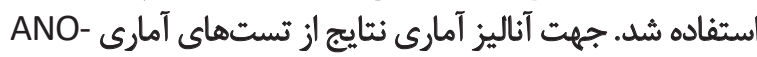

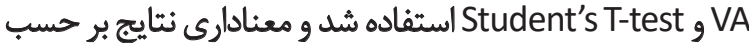

Pن $P<1 \cdot \Delta$

\begin{tabular}{|c|c|c|c|}
\hline غلظت اوليه عصاره (ميكروكرم بر ميلى ليتر) & كلسترول (درصد) & (د, 7. Span & كد فرمولاسيون \\
\hline ه... & 1. & q. & F1 \\
\hline$\Delta \ldots$ & r. & A. & F2 \\
\hline$\Delta \ldots$ & r. & $\gamma$. & F3 \\
\hline
\end{tabular}

جدول ا. فرمولاسيونهاى مختلف نانوذره و درصد تركيبات استفادهده در اين فرمولاسيونها

فنقاثن 


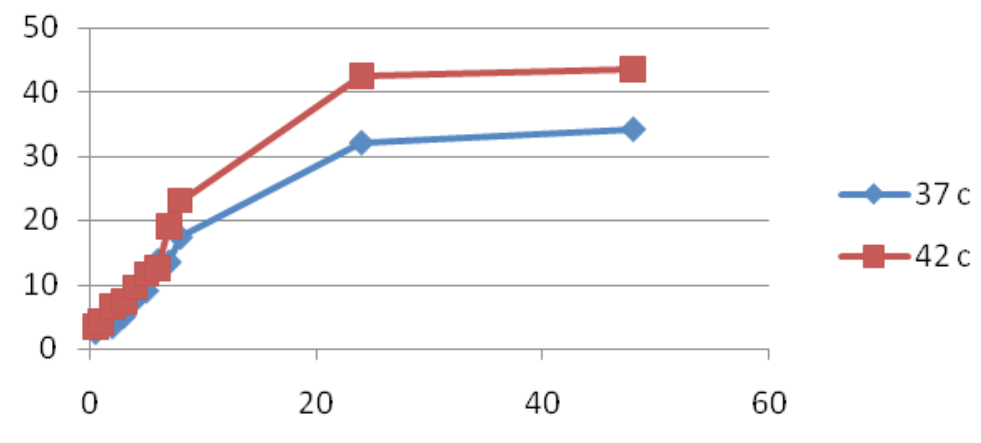

أنّانث

تصوير ا. نمودار مربوط به رهايش عصاره از نانوسامانه ليبوزومى در بافر PBS در دو دوماى TV و Fr درجه سانتى Fراد.

از دستكاه ميكروسكوب الكترونى نمايه" را أنمايش مي دهند.

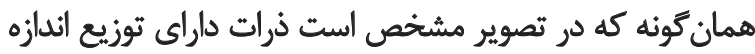

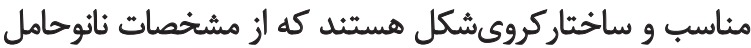

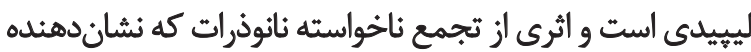

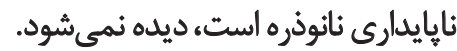

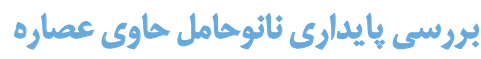

به منظور بررسى هايدارى ساختّارى نانوحامل توليدشده، عدم

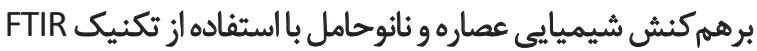

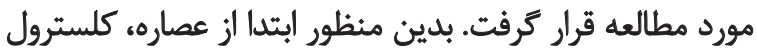

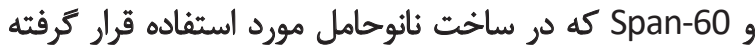

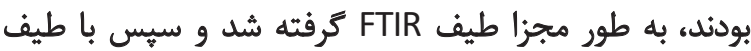

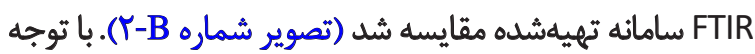
به طيفهاى بهدستآمده جنين تحليل هي شئود كه در سامائه

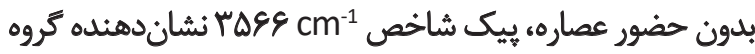

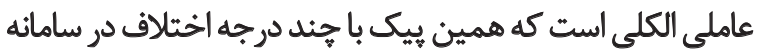

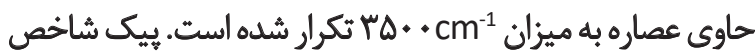

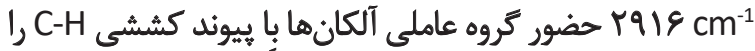

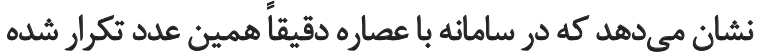

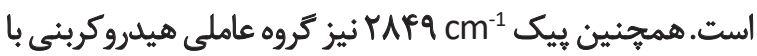

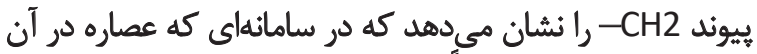

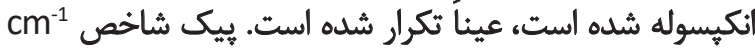

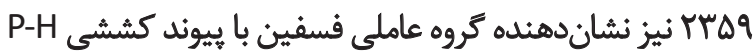

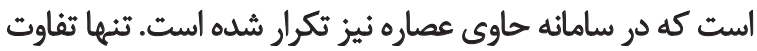
در سامانه حاوى عصاره حضور ئيك اضافه

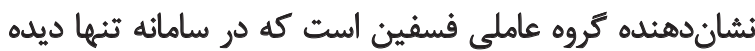

$$
\text { نمى شئند. }
$$

به طور كلي، با مقايسه طيف FTIR هر سه نمونه عصاره، سامانه

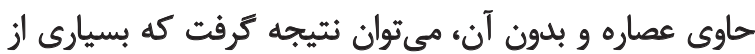

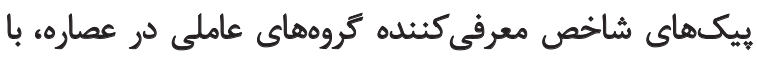

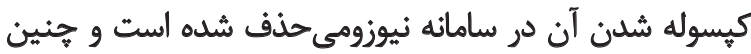

آزادسازى ادامه مي دهد كه نشاندهئده ييوستكى رهايش است.

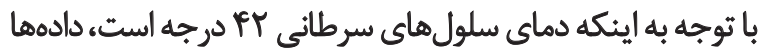

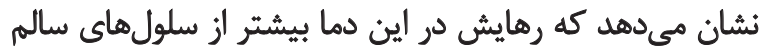

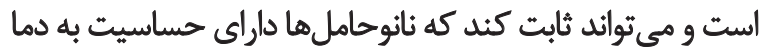

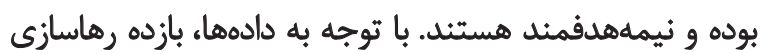

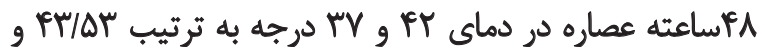

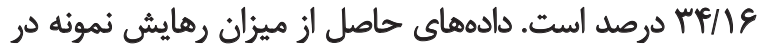

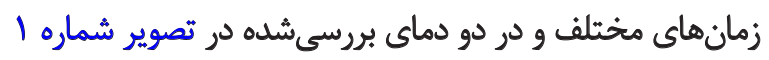

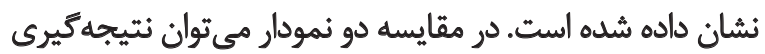

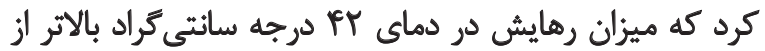

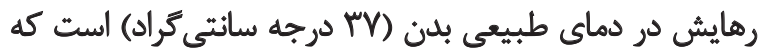

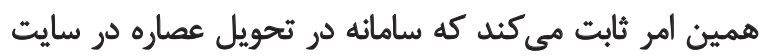

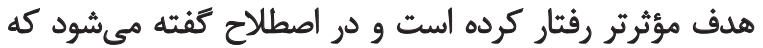

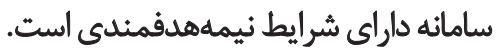

بورسي و مقايسه أندازه و بار سطحي نانوحامل نيوزومي حاوي

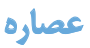
با توجه به اهميت اندازه و بار سطحى نائوحامل در بسيارى از

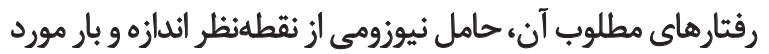

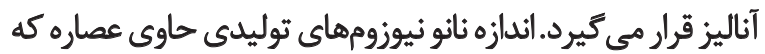

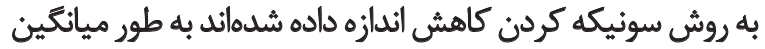

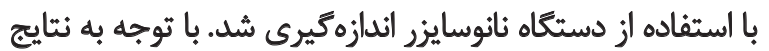

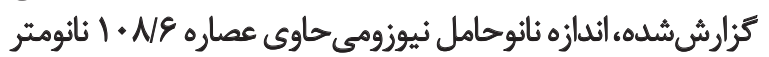
تعيين شد.

يتائسيل زتاى سطح نانو نيوزومهاى توليدى نيز با باستفاده از

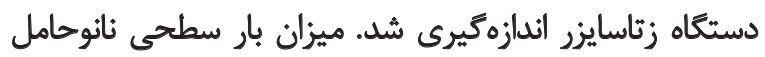

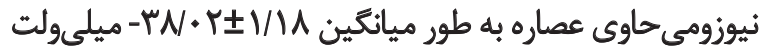

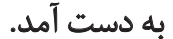
بروسي مورفولؤى نانوذرات نيوزومى تصوير شماره Y-A مورفولوريى نانوذرات ساختششده با استفاده 


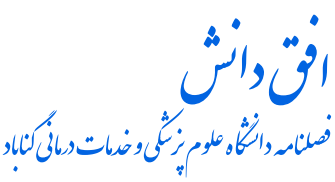
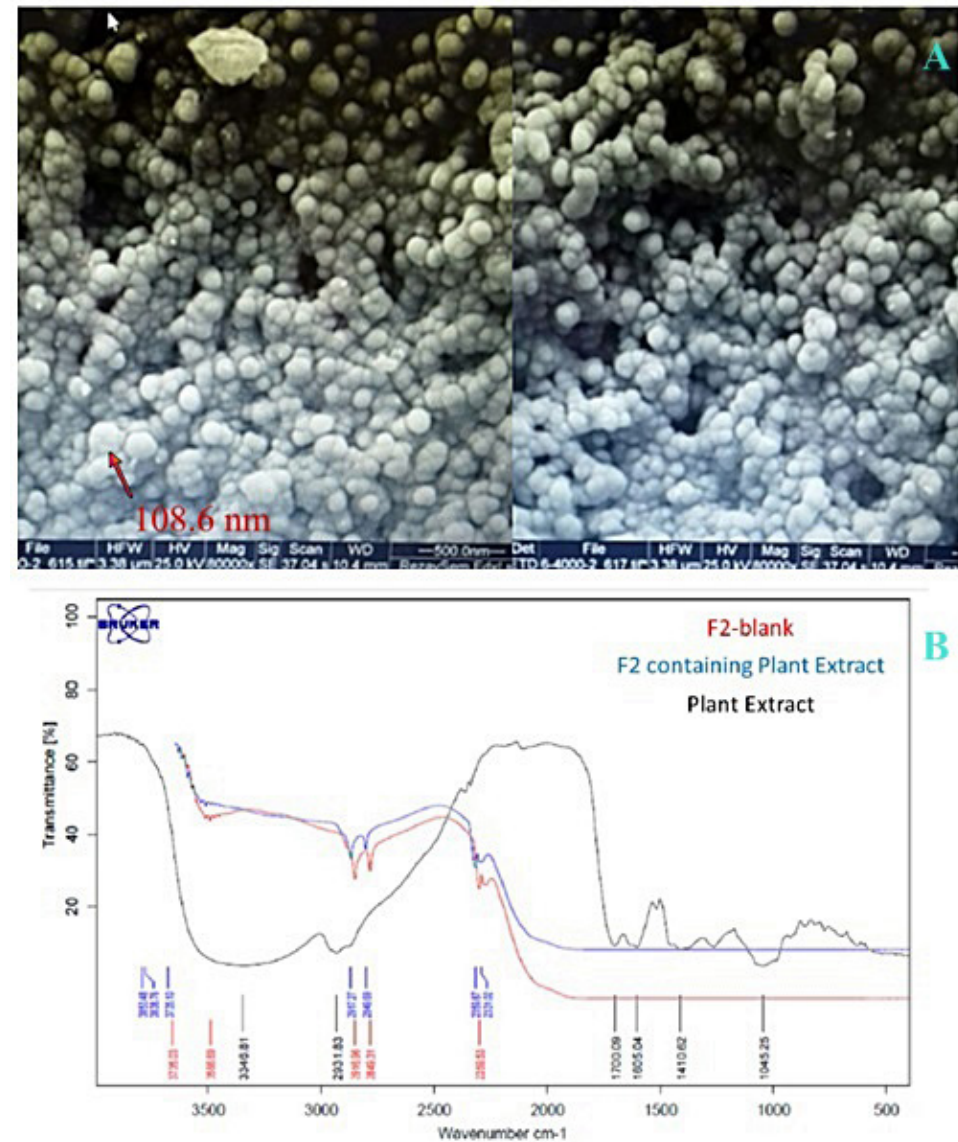

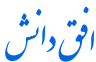

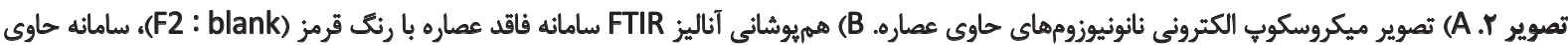

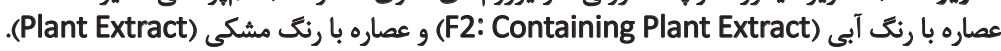

MG-63 بروسى ورود ناثو حامل نيوزومى به سلول سرطاني

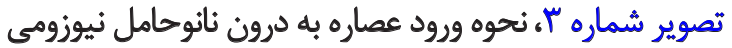

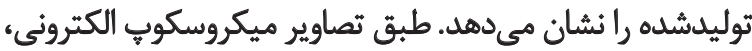
باركذارى عصاره در نانو حامل در حد قابل قبو مبولى انجام شده است. تصاوير كرفتهشده از ميكروسكوب فلورست، بهخوبى گواه بر

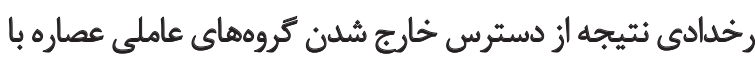

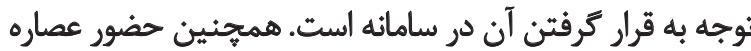

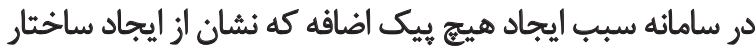

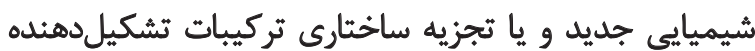

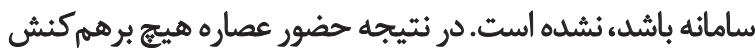
شيميايى ناخواستهاى با سامانه برقرار نكرده است.

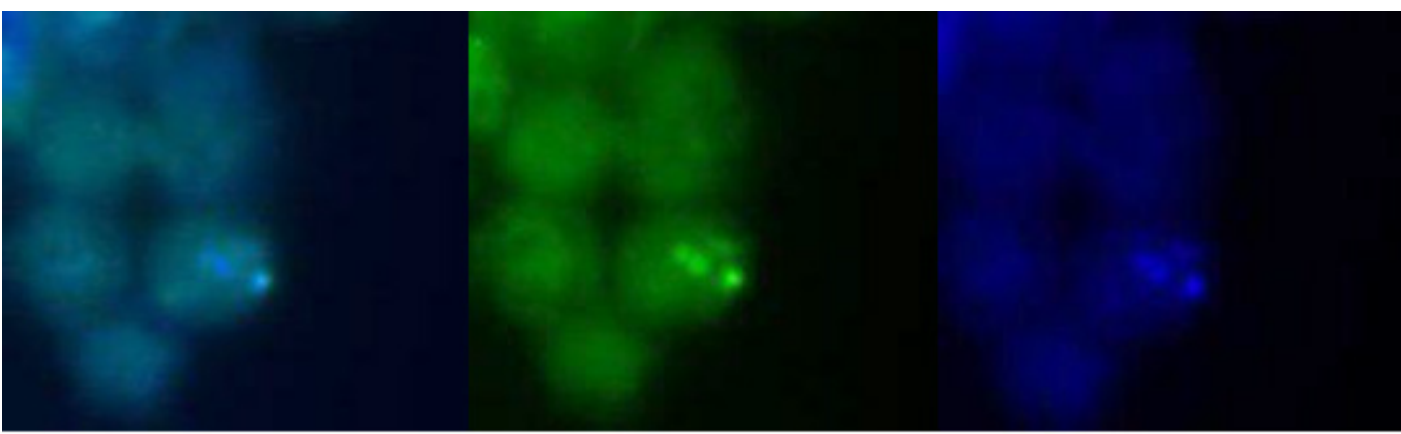

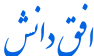

تصوير با. تصوير ميكروسكوب الكترونى.تصوير هسته رنكآميزى شده با رنك DAPI (سمت جب)، تصوير سامانه طراحىشده كه به سلول وارد شده (وسط) و تلفيق

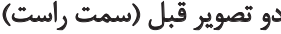


MG-63 MTT Assay

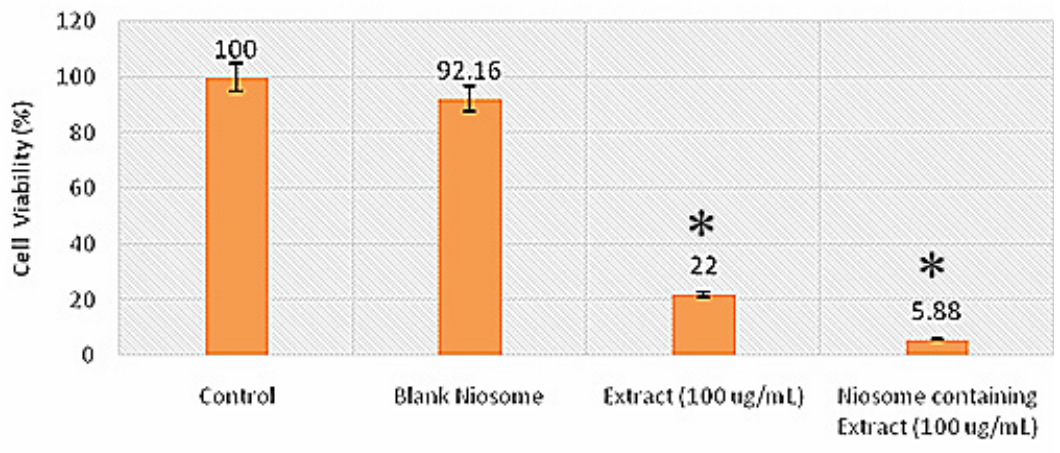

انتوانث

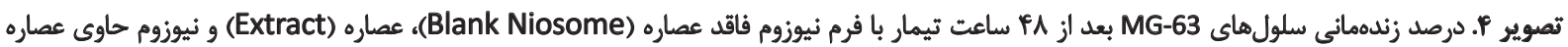
(Niosome containing Extract)

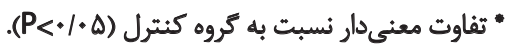

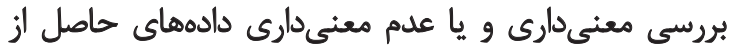

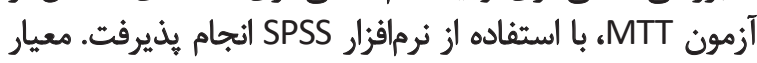

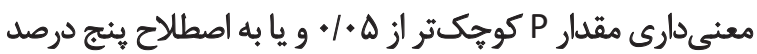

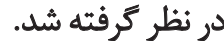

\section{ث}

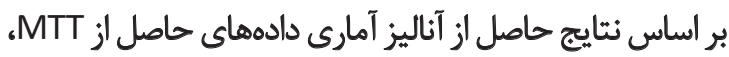

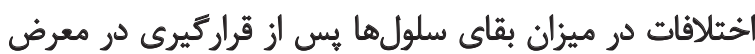

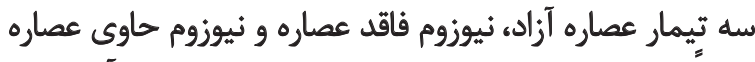

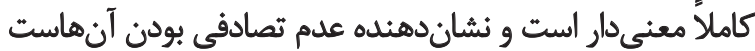

. $(P<\cdot 1 \cdot \Delta)$

شيوههاى مرسوم جهت درمان سرطان، بر ريشهكن كردن

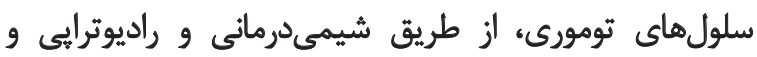

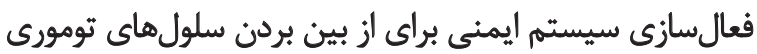

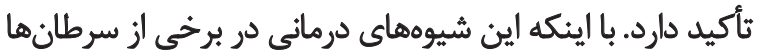

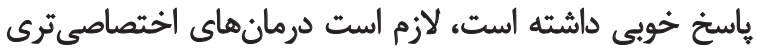

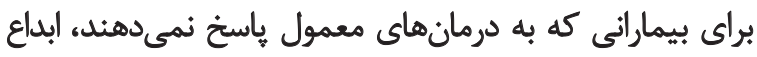

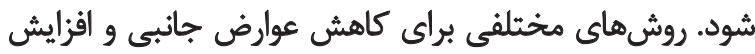

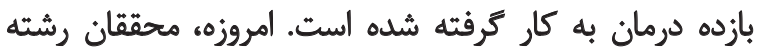

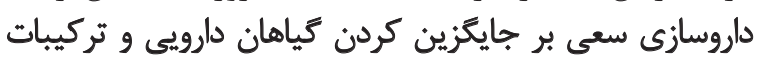

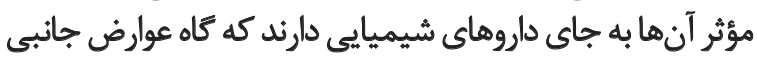

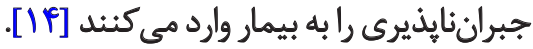
در مطالعه اخير، سه سامانه نانونيوزومى مختلف با استفاده از

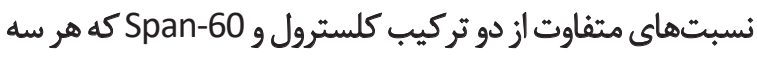

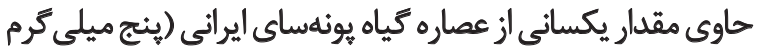

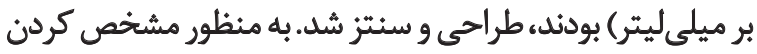

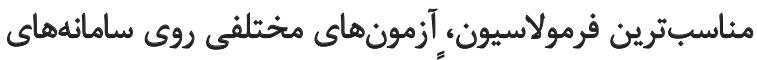

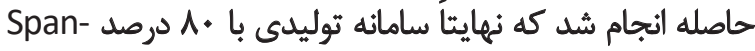

ورود نانوسامانه به درون سلول و وقوع برداشت سلولى است (به

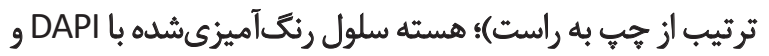

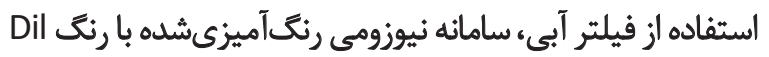

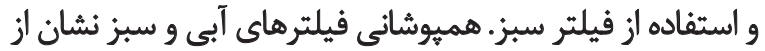

$$
\text { ورود نانوسامائه به درون سلول دارد. }
$$

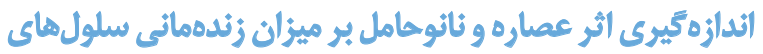
MG-63

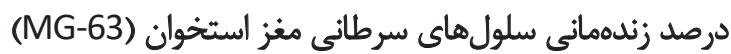

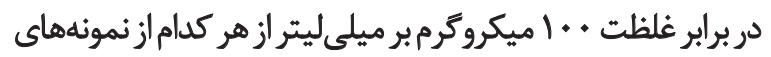

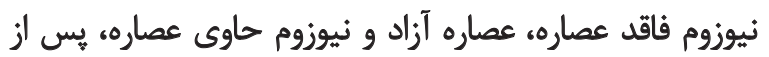

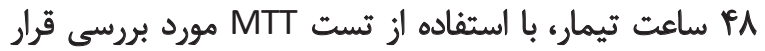

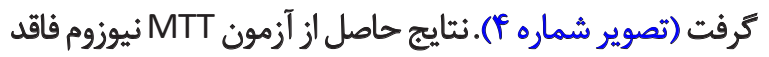

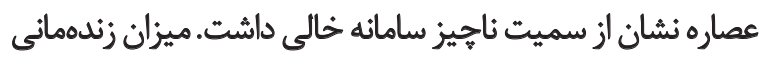

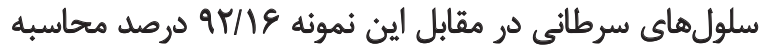

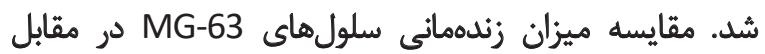

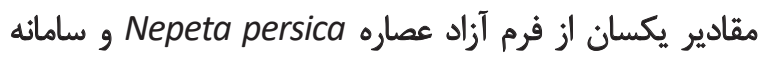

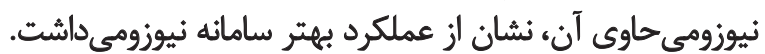

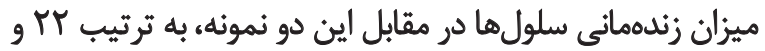

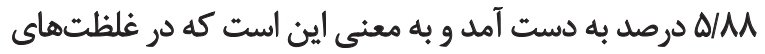

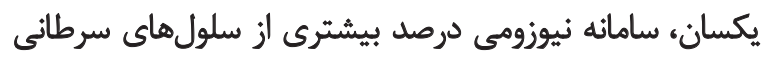

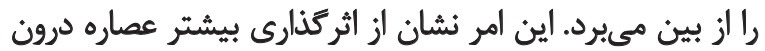

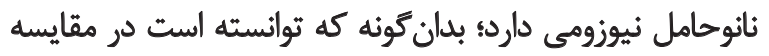

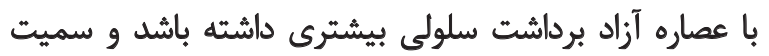

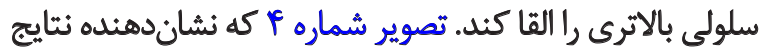

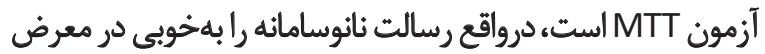

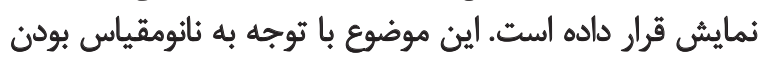

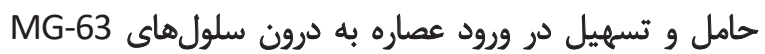
توجيهيذير است. 
مى دهد و باعث كاهش اثرات نامطلوب آن روى بافتهاى غيرهدف

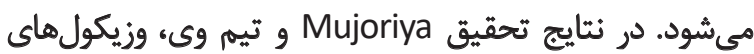

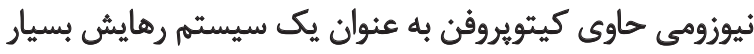

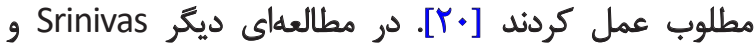

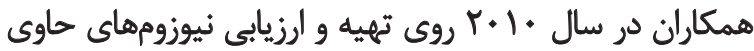

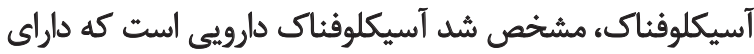
خواص درمانى ضعيف و نيمه عمر زيستى كوتاه است. هدف آنهائها

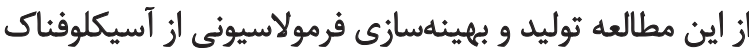

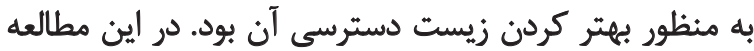

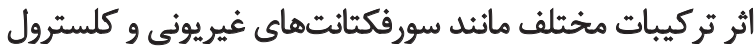

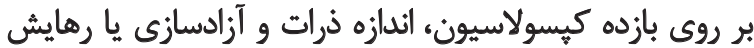

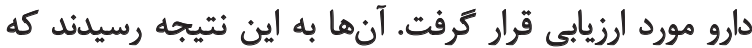

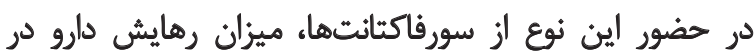

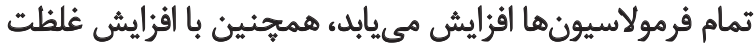

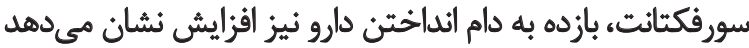

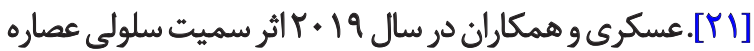

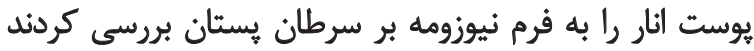

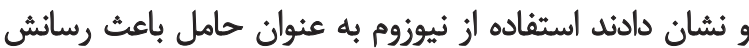

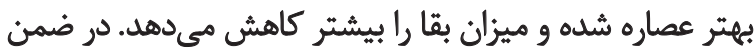

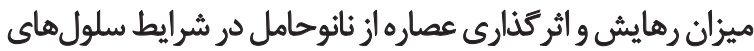

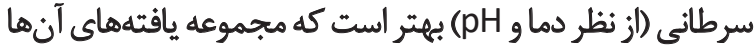

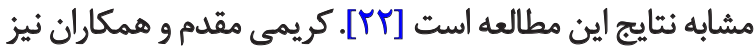

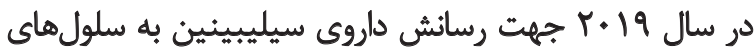

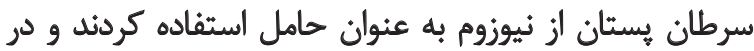

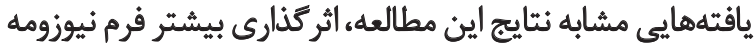

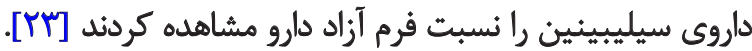

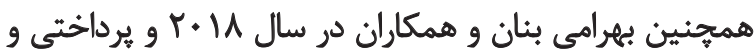

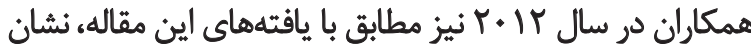

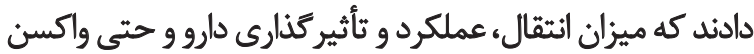

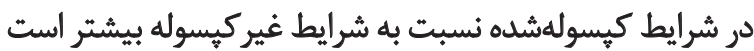

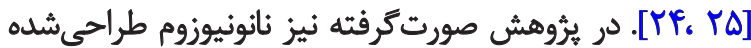

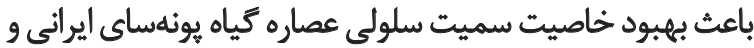

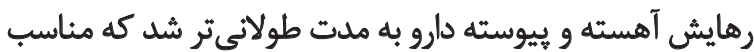

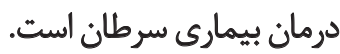

\section{تئيجلَّيرى}

استفاده از علم نانوتكنولوزى در زمينه يزشكى و دارئي داروسازى

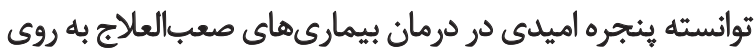

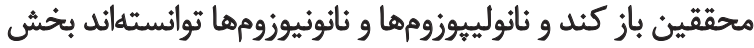

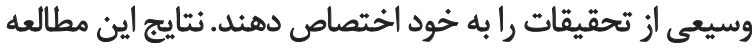

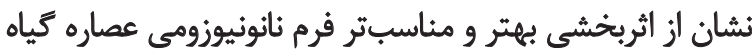

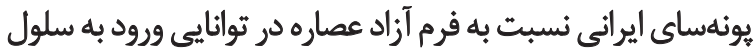
و القاى اثرات ضدسرطانى داشت.
60 و • ب درصد كلسترول به عنوان فرمولاسيون برتر شناسايى

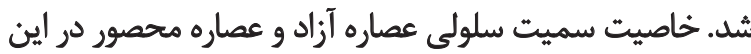

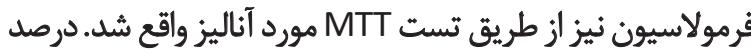

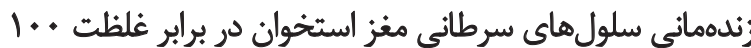

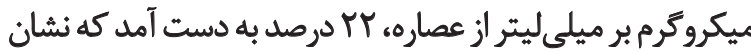

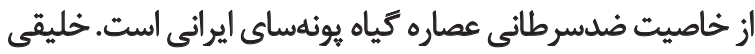

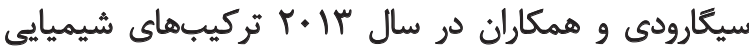

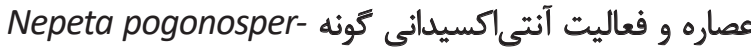
ma

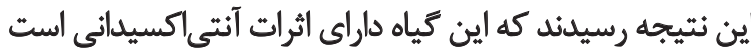

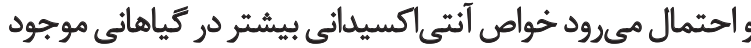

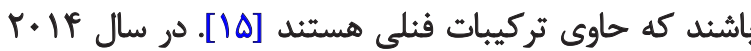

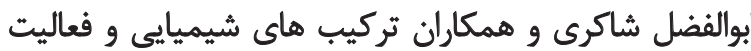

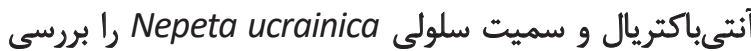
كردند و به اين نتيجه رسيديند كه عصاره اين كيدي سياه داراي فعاليت

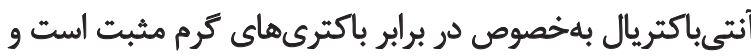

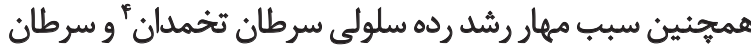

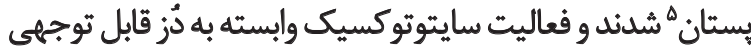
در مقابل MCF-7 و A2780 است [ع 19].

از ديكر روشهايى كه بهشدت مورد توجه محققين در زمينه

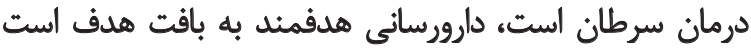

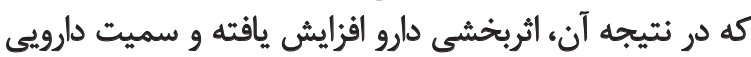

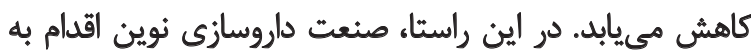

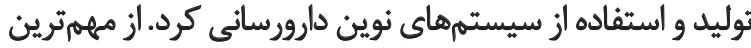

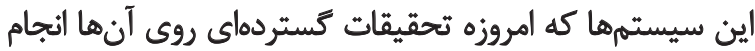

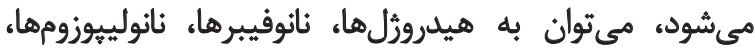

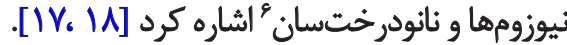
در تحقيق حاضر، مقايسه تأثير سميت سلولى نيوزوم حاوى

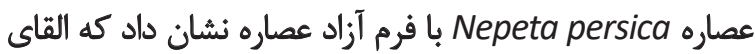

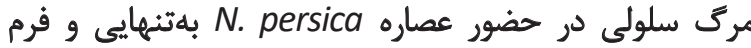

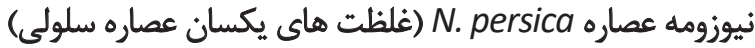

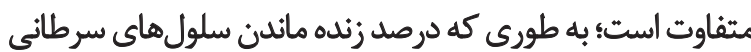

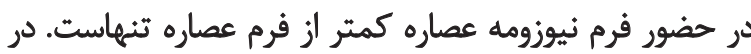

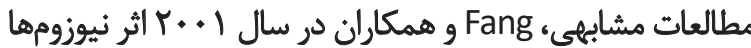

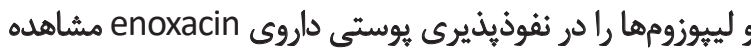

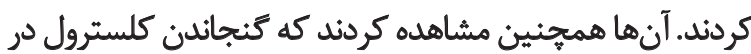

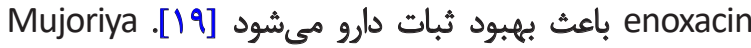

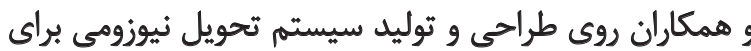

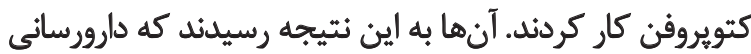

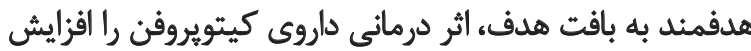




\section{ملاحظات اخلاقى}

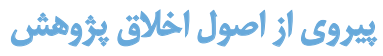

اين يرُوهش بر اساس اصول اخلاقي حفاظت از آزمودنى أزهاى

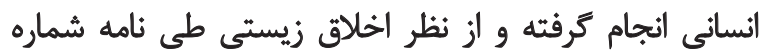

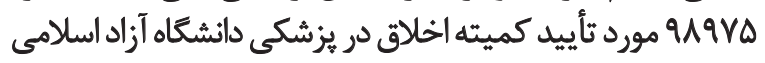

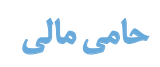

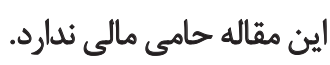

$$
\text { مشاركت نويسئدمان }
$$

تمام نويسئدكان در طراحى، اجرا و نتارش همه بخشهاى ئروهش حاضر مشاركت داشتهاند.

$$
\text { تعارض مثاقع }
$$

هيج گونه تعارض منافعى توسط نويسند

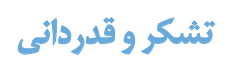

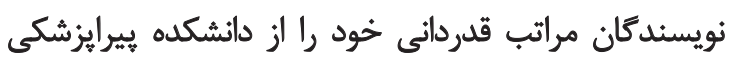

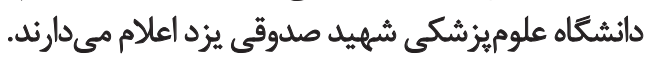




\section{References}

[1] Hart BL. The evolution of herbal medicine: Behavioural perspectives. Animal Behaviour. 2005; 70(5):975-89. [DOI:10.1016/j.anbehav.2005.03.005]

[2] Geller DS, Gorlick R. Osteosarcoma: A review of diagnosis, management, and treatment strategies. Clinical Advances in Hematology \& Oncology. 2010; 8(10):705-18. [PMID]

[3] Moghassemi S, Hadjizadeh A. Nano-niosomes as nanoscale drug delivery systems: An illustrated review. Journal of Controlled Release. 2014; 185:22-36. [DOI:10.1016/j.jconrel.2014.04.015] [PMID]

[4] Yang XB, Wu WY, Long SQ, Deng H, Pan ZQ. Effect of gefitinib plus Chinese Herbal Medicine (CHM) in patients with advanced non-small-cell lung cancer: A retrospective case-control study. Complementary Therapies in Medicine. 2014; 22(6):1010-8. [DOI:10.1016/j.ctim.2014.10.001] [PMID]

[5] Cragg GM, Newman DJ. Plants as a source of anti-cancer agents. Journal of Ethnopharmacology. 2005; 100(1-2):72-9. [DOI:10.1016/j. jep.2005.05.011] [PMID]

[6] Nobili S, Lippi D, Witort E, Donnini M, Bausi L, Mini E, et al. Natural compounds for cancer treatment and prevention. Pharmacological Research. 2009; 59(6):365-78. [DOI:10.1016/j.phrs.2009.01.017] [PMID]

[7] Evans WC, Evans D, Trease GE. Trease and Evans pharmacognosy. Philadelphia: Saunders/Elsevier; 2009. https://books.google.com/ books?id=ujetPwAACAAJ\&dq

[8] Baser KHC, Oözek T, Yildiz B, Bahçecioglu Z, Tuümen G. Composition of the essential oil of Nepeta fissa C.A.Meyer. Journal of Essential Oil Research. 2000; 12(1):27-8. [DOI:10.1080/10412905.2000.9712033]

[9] Rapisarda A, Galati EM, Tzakou O, Flores M, Miceli N. Nepeta sibthorpii Bentham (Lamiaceae): Micromorphological analysis of leaves and flowers. II Farmaco. 2001; 56(5-7):413-5. [DOI:10.1016/S0014827X(01)01050-3]

[10] Tzakou O, Harvala C, Galati EM, Sanogo R. Essential oil composition of Nepeta argolica Bory et Chaub. subsp. argolica. Flavour and Fragrance Journal. 2000; 15(2):115-8. [DOI:10.1002/(SICl)10991026(200003/04)15:2<115::AID-FFJ877>3.0.CO;2-9]

[11] Mozaffarian V. [A dictionary of Iranian plant, names: Latin, English, Persian (Latin-English-Persian)]. $2^{\text {nd }}$ ed. Tehran: Farhang Moaser; 1998. http://opac.nlai.ir/opac-prod/bibliographic/555105

[12] Haghiralsadat F, Amoabediny G, Sheikhha MH, Zandieh-Doulabi B, Naderinezhad S, Helder MN, et al. New liposomal doxorubicin nanoformulation for osteosarcoma: Drug release kinetic study based on thermo and pH sensitivity. Chemical Biology \& Drug Design. 2017; 90(3):368-79. [DOI:10.1111/cbdd.12953] [PMID]

[13] Mosmann T. Rapid colorimetric assay for cellular growth and survival: Application to proliferation and cytotoxicity assays. Journal of Immunological Methods. 1983; 65(1-2):55-63. [DOI:10.1016/00221759(83)90303-4]

[14] Zarei M, Arjmand M, Mohammadi M, Chiani M, Ebrahimi H, Akbarzadeh Khiavi A. [Preparation of nanoniosomal Paclitaxel formulation and survey of its cytotoxic effect on breast cancer cell line (MCF-7) (Persian)]. New Cellular \& Molecular Biotechnology Journal. 2013; 3(12):17-23. http://ncmbjpiau.ir/article-1-438-en.pdf

[15] Khalighi-Sigaroodi F, Ahvazi M, Ebrahimzadeh H, Rahimifard N. [Chemical composition of the essential oil and antioxidant activities, total phenol and flavonoid content of the extract of Nepeta pogonosperma
(Persian)]. Journal of Medicinal Plants. 2013; 4(48):185-98. http://jmp. ir/article-1-72-en.html

[16] Shakeri A, Khakdan F, Soheili V, Sahebkar AH, Rassam GA, Asili J. Chemical composition, antibacterial activity, and cytotoxicity of essential oil from Nepeta ucrainica L. spp. kopetdaghensis. Industrial Crops and Products. 2014; 58:315-21. [DOI:10.1016/j.indcrop.2014.04.009]

[17] Moghimipour E, Kouchak M, Bahmandar R. [Nano-liposomes as new drug delivery carriers (Persian)]. Jundishapur Scientific Medical Journal. 2013; 12(5):467-83. http://jsmj.ajums.ac.ir/article_49795_en.html

[18] Tiwari G, Tiwari R, Sriwastawa B, Bhati L, Pandey S, Pandey P, et al. Drug delivery systems: An updated review. International Journal of Pharmaceutical Investigation. 2012; 2(1):2-11. [DOI:10.4103/2230973X.96920] [PMID] [PMCID]

[19] Fang JY, Hong CT, Chiu WT, Wang YY. Effect of liposomes and niosomes on skin permeation of enoxacin. International Journal of Pharmaceutics. 2001; 219(1-2):61-72. [DOI:10.1016/S0378-5173(01)00627-5]

[20] Mujoriya RZ, Bodla RB. Design and development of niosomal delivery system for ketoprofen. Advances in Life Science and Technology. 2012; 3:1-13. https://www.iiste.org/Journals/index.php/ALST/article/ view/963

[21] Srinivas S, Anand Kumar Y, Hemanth A, Anitha M. Preparation and evaluation of niosomes containing aceclofenac. Digest Journal of Nanomaterials and Biostructures. 2010; 5(1):249-54. http://www.chalcogen. ro/249_Srinivas.pdf

[22] Askari M, Nikoonahad Lotfabadi N. [Evaluation of niosomal nano-carriers capabilities on toxicity preservation and delivery of pomegranate peel extract in cell culture conditions (MCF-7 cell line of breast cancer) (Persian)]. Daneshvar Medicine: Basic and Clinical Research Journal. 2018; 26(5):9-20. http://daneshvarmed.shahed.ac.ir/article-1-2015-en. html

[23] Karimi-Moghddam A, Nikoonahad Lotfabadi N, Haghiralsadat BF, Majdizadeh M. [Investigating the effect of lipid nanoparticles containing silibinin anticancer drug on the growth of breast cancer MCF-7 cell line (Persian)]. Journal of Torbat Heydariyeh University of Medical Sciences. 2018; 6(4):1-12. http://jms.thums.ac.ir/article-1-563-en.pdf

[24] Bahrami-Banan F, Sheikhha MH, Ghasemi N, Majdizadeh M, Haghiralsadat BF. [Preparation and study of nano-niosomes containing doxorubicin and evaluation of its toxicity on acute myeloblastic leukemia cell line KG-1 (Persian)]. Journal of Payavard Salamat. 2018; 12(4):309-23. http://payavard.tums.ac.ir/article-1-6592-en.html

[25] Pardakhty A, Shakibaie M, Daneshvar H, Khamesipour A, Mohammadi-Khorsand T, Forootanfar H. Preparation and evaluation of niosomes containing autoclaved Leishmania major : A preliminary study. Journal of Microencapsulation. 2012; 29(3):219-24. [DOI:10.3109/02652048.2 011.642016] [PMID] 
This Page Intentionally Left Blank 